\title{
Treatment of Cutaneous Leishmaniasis and Insights into Species-Specific Responses: A Narrative Review
}

\author{
Rajamanthrilage Kasun Madusanka (D) - Hermali Silva \\ Nadira D. Karunaweera (iD
}

Received: January 8, 2022 / Accepted: January 31, 2022 / Published online: February 22, 2022

(c) The Author(s) 2022

\begin{abstract}
Cutaneous leishmaniasis (CL) is a complex skin infection that has imposed a heavy burden on many developing countries and is caused by more than 20 Leishmania species. This disease is predominantly associated with disfiguring scars and major social stigma upon infection. The severity of the disease seemingly depends on many factors including the species of parasite, the host, region of endemicity, socio-economic status and the accessibility to health facilities. Despite myriad studies that have been performed on current and novel therapies, the treatment outcomes of CL remain contentious, possibly because of the knowledge gaps that still exist. The differential responses to the current CL therapies have become a major drawback in disease control, and the dearth of information
\end{abstract}

on critical analyses of outcomes of such studies is a hindrance to the overall understanding. On the basis of currently available literature on treatment outcomes, we discuss the most effective doses, drug susceptibilities/resistance and treatment failures of the Leishmania genus for both monotherapy and combination therapy. This review focuses on the available treatment modalities for CL caused by different Leishmania species, with insights into their species-specific efficacies, which would inform the selection of appropriate drugs for the treatment and control of leishmaniasis.

Keywords: Cure rate, Cutaneous leishmaniasis; Drug resistance; Efficacy; Leishmania; Speciesspecific; Therapy; Treatment

Rajamanthrilage Kasun Madusanka and Hermali Silva contributed equally to this work.

R. K. Madusanka · H. Silva · N. D. Karunaweera ( $₫)$ Department of Parasitology, Faculty of Medicine, University of Colombo, No. 25, Kynsey Road, Colombo 8, Sri Lanka

e-mail: nadira@parasit.cmb.ac.lk 


\section{Key Summary Points}

Treatment of cutaneous leishmaniasis (CL)

is challenging because of the

inconsistencies in host treatment

responses, which are multifactorial and

include parasite species-specific factors.

Most of the conventional drugs that have been used for decades have become ineffective with species-level unresponsiveness.

Antimonials are the commonly used firstline treatment in most countries with variable treatment outcomes.

Leishmania major appears predominantly susceptible to most of the current treatment methods unlike other CLcausing parasite species.

Combination treatment is more effective against a wide array of leishmaniasis cases where monotherapy has failed.

\section{INTRODUCTION}

Leishmaniasis is caused by protozoan parasites of genus Leishmania and transmitted to humans by the bite of Leishmania-infected Phlebotomus or Lutzomyia sandflies [1]. The disease is endemic in more than 98 countries, with almost 350 million people at risk and around 2 million new cases reported worldwide annually [2]. At the global level, most annual cases occurred in western Asia, central Asia, the Americas and the Mediterranean basin [3]. Moreover, the poverty and lack of healthcare facilities potentiate contracting the disease and increasing the mortality rate $[4,5]$. Leishmaniasis manifests in three major clinical forms: visceral leishmaniasis or kala-azar, cutaneous leishmaniasis (CL) and mucocutaneous leishmaniasis; the cutaneous form is the most common of all types [2].

According to the World Health Organization (WHO) definitions, CL is found in both the Old and New Worlds [2]. Old World cutaneous leishmaniasis (OWCL), mainly seen in the Eastern hemisphere, is caused by L. donovani, L. infantum, L. major, L. tropica and L. aethiopica, and New World cutaneous leishmaniasis (NWCL), which is more common in Central and South America, is predominantly caused by L. braziliensis, L.panamensis, L.guyanensis, L.amazonensis, L.mexicana and L.peruviana $[6,7]$. Disseminated CL, mostly reported in north-eastern Brazil [8, 9], is comparatively more drug sensitive and manageable than diffuse CL which is more likely to be drug resistant. Moreover, the diffuse CL due to L. mexicana and L.amazonensis is considered a more difficult form to treat with contemporary treatment methods [10].

Cutaneous leishmaniasis causes skin lesions upon exposure to infection and leaves disfiguring scars and disabilities [11-13]. Lesions caused by CL may be limited to a specific region on the skin (localized CL) or give rise to multiple lesions on a large area of the body (diffused CL and disseminated $\mathrm{CL}$ ), which are notoriously difficult to treat [10]. Moreover, the clinical presentation of CL lesions may vary depending on the host immunity and causative Leishmania species. Although typical CL lesions are painless and tend to self-heal in 3-18 months, in some cases, particularly the ones caused by L. tropica, L. major and L.aethiopica, are associated with long-lasting multiple lesions and severe scarring [5]. Therefore, treatment of CL is of great importance to minimize the probable complications.

Of note, the control of CL largely depends on early diagnosis, and expeditious treatment [14]. In accordance with the priorities of WHO and world health developmental policies, there is a huge demand for studies focused on the proper use of drugs and treatment methods to cure neglected tropical diseases like leishmaniasis [15]. Successful CL treatment accelerates healing, reduces scarring and reduces the risk of further complications. However, the treatment outcome may depend on factors such as the causative parasite species, especially its pathogenicity, host factors and geographic location [11]. To date, a number of antileishmanial treatments have been introduced such 
as chemotherapy [16], cryotherapy [17], thermotherapy [18] and several less frequently used alternative methods [19]. Commonly used leishmanicidal drugs include pentavalent antimonials [20-22], amphotericin B [23, 24], miltefosine $[25,26]$, paromomycin $[27,28]$ and, topical and systemic azoles [29, 30]. These chemotherapeutic agents have immensely helped to reduce CL transmission and alleviate the disease burden over decades. Unfortunately, the effective use of these therapies has been barred by limitations such as the emergence of poor responsiveness resulting in low efficacy, need for prolonged treatment, frequent recurrences and serious side effects [31, 32]. Despite the availability of several therapies for leishmaniasis, there is no universal cure for all types of CL and the efficacy of the commonly used prevalent antimonials is species-dependent $[29,33,34]$. Moreover, the published literature reviews based on species-specific effectiveness of CL treatments are extremely scarce.

There is an urgent need for the discovery of efficacious, affordable and safe treatment strategies for CL, including those applicable in a species-specific manner and bridging the knowledge gaps on species-specific treatment modalities. Accordingly, the aim of this review is to summarize the therapeutic efficacy of currently available treatment strategies of $\mathrm{CL}$, highlighting the species-specific treatment response.

\section{Statement of Ethics Compliance}

This article is based on previously published work and does not contain novel data or information related to human or animal studies.

\section{ANTILEISHMANIAL MONOTHERAPY}

\section{Antimony}

Although several antileishmanial drugs have been used during the past few decades, unarguably, antimonials remain the first-line treatment for CL in most countries irrespective of the causative agent and clinical form of the lesions. Sodium stibogluconate (SSG) and meglumine antimoniate (MA) are the two major formulations of antimonials in current use to treat CL. Among different mechanisms of action of antimonials, a prominent dual action against CL infection is seen: firstly, antimonials activate the macrophages to kill the infected parasites; secondly, $\mathrm{Sb}(\mathrm{V})$, the prodrug, is reduces to active $\mathrm{Sb}$ (III) that targets inhibition of trypanothione reductase which eventually leads to parasite killing [35]. Accumulating evidence suggests that antimonials increase the expression of aquaglyceroporin (AQP1) and inhibit DNA topoisomerase, glycolysis pathways, ATP/ GTP synthesis and glucose catabolism resulting in decreased viability of Leishmania parasites [34, 36-39]. Current uses notwithstanding, the emergence of drug resistance, especially in the Indian subcontinent with $60 \%$ unresponsiveness [2], has been an instigator for the discovery of alternative treatments for decades.

Genetically distinct populations of Leishmania are able to show varied responses to antimony with antimony-resistant phenotypes developing as a result of genetic mutations of parasites [40]. Also, the region of endemicity plays a pivotal role in differential antimonial responses. Cutaneous leishmaniasis caused by L. (V.) braziliensis in Peru, Brazil and Guatemala has shown 69.6\%, 50.8\% and $96.0 \%$ chemotherapeutic sensitivity, respectively, towards $\mathrm{Sb}(\mathrm{V})$ therapy $(20 \mathrm{mg} / \mathrm{kg} / \mathrm{day}$ for 20 days) [21, 22, 41]. Therefore, it could be hypothesised that either a genetic variation in the parasites of the same species or the differences in the genetic composition and immunity of the people within the regions have affected the therapeutic response. Cutaneous leishmaniasis caused by L. aethiopica has less sensitivity to SSG and appears slightly resistant to antimonial drugs in vitro, compared to the high SSG sensitivity that is reported in L. donovani $[42,43]$. It has also been suggested that selfhealing CL species such as L. major were fairly sensitive to oxidative stress and showed increased susceptibility to antimonial drugs than other species [44]. The cure rate (CR) of CL due to L.tropica treated with intralesional administration of SSG was higher and more 
efficient than intramuscular administration of SSG in a randomized controlled clinical trial [45]. Furthermore, intrinsic differences were reported in $\mathrm{Sb}$ (III) sensitivities upon exposure to concentration series of potassium antimony tartrate whereas $\mathrm{EC}_{50}$ (effective concentration) data showed 2.6, 3 and 6 times more resistance to $\mathrm{Sb}$ in $\mathrm{CL}$ caused by L. braziliensis, L. tropica and L.panamensis, respectively, compared to L. major [34].

With respect to the dosage, intravenous antimonial treatment at a daily dose of $20 \mathrm{mg}$ / $\mathrm{kg}$ for 10 consecutive days could produce better cure rates against CL caused by L. panamensis and L. braziliensis [46, 47]. Furthermore, CL caused by $L$. major showed moderate CRs with the aforementioned treatment regimen [48]. However, CL caused by L. (V.) panamensis cured $100 \%$ after $20 \mathrm{mg} / \mathrm{kg} /$ day for 20 days, compared to the lower CR (64\%) with a dose of $10 \mathrm{mg} /$ $\mathrm{kg} /$ day, during a course of 20 days of intravenously administered SSG [49]. Another study on L. braziliensis panamensis supported the fact that 20-day intramuscular administration of SSG at a daily dose of $13 \mathrm{mg} / \mathrm{kg}$ resulted in only a 68\% CR [30]. Accordingly, a 20-day SSG administration at a daily dose of $20 \mathrm{mg} / \mathrm{kg}$ seems to be the most effective regimen to treat a wide array of CL cases, although distinct species-level variations exist. The lesser doses seemed comparatively insufficient $[7,21,49]$ to produce a wide antileishmanial effect, mostly due to the discrepancies in the degree of sensitivity to antimonials between species and even within the same parasites species. On the other hand, administration of antimonials at high concentrations for a shorter time may effectively target the infection and ultimately reduces the cost, healing time and the systemic toxic effects. The most effective and optimum dosage of $\mathrm{Sb}(\mathrm{V})$ therapy appears to be $20 \mathrm{mg} / \mathrm{kg} /$ day for 20-28 days. L. major, L. donovani, L. (V.) braziliensis (in Guatemala) and L. tropica seemed more sensitive to antimonial drugs compared to the lower susceptibility reported with L.aethiopica, L.panamensis and L. (V.) braziliensis (in Brazil). Nevertheless, Leishmania species like L.braziliensis and L. panamensis had contrasting outcomes with antimonial treatment. Furthermore, the unresponsiveness reported, and the treatment failure of antimonial drugs must be extensively investigated to find out the remedies for emerging resistance and for the longevity of the existing therapies.

\section{Miltefosine}

The orally administered drug miltefosine (hexadecylphosphocholine) was first used as an anticancer agent before it was suggested as a treatment for leishmaniasis [25, 50]. Studies have proven antileishmanial activities associated with its ability to derange sterol and phospholipid biosynthesis, and cell signal transduction of parasites [51]. In some instances, where antimony resistance had become a challenge, miltefosine was used as the secondline drug [25] and was effective on diffused CL producing $80-90 \%$ parasitological improvement within 2 months [52]. Nonetheless, this regime resulted in high probability of relapsing with the development of new infection in the majority of cases [52].

Miltefosine has been strongly recommended for patients with CL due to L. guyanensis and L. panamensis [33] albeit with slightly paradoxical research outcomes with several other CL species. For instance, miltefosine showed a robust decline in response against $L$. major $\mathrm{CL}$ and slow response against L. infantum $[33,53]$. However, an in vitro assessment suggested high efficacy for CL due to L. donovani, but was unsatisfactory against L. major. In contrast, CL due to L.major in Iran was more responsive, showing $92.9 \%$ CR compared to that of $83 \%$ with MA. These CRs were almost compatible with the results obtained in patients with American cutaneous leishmaniasis (ACL) treated with $150 \mathrm{mg}$ daily for 28 days [54]. According to a placebo-controlled trial conducted in Guatemalan patients with $\mathrm{CL}$, the $\mathrm{CR}$ for L. braziliensis (ca. 50\%) seemed unfavourable, but in the Colombian context it was amply responsive (CR 91\%) against L. panamensis [26]. In contrast, in Brazil, two randomized controlled trials revealed that the therapeutic outcomes of CL due to L. braziliensis or L. (Viannia) guyanensis were outstanding in patients treated 
with miltefosine compared to patients treated intravenously with $\mathrm{Sb}(\mathrm{V})[55,56]$. As a whole, a frequently recommended treatment regimen for miltefosine is $1.5-2.5 \mathrm{mg} / \mathrm{kg} /$ day (orally) for 28 days $[26,53,55-58]$. According to the prevailing data, miltefosine is an effective and safe drug for treating CL caused by L.guyanensis, L. panamensis and L.donovani, whereas CL caused by L.infantum and L.braziliensis appeared to be more resistant.

\section{Paromomycin}

Paromomycin (PM), an aminoglycosideaminocyclitol antibiotic, is used in some countries to treat CL as a topical or parenteral drug $[59,60]$. However, the systemic use of PM is less common. PM acts as an inhibitor of Leishmania parasite propagation by interfering with protein translation, with only a minute influence on human cell counterparts [61, 62]. According to the Pan American Health Organization (PAHO) guidelines, PM has not yet been recommended as a treatment for CL [63]. In Ethiopia, as per their health guidelines, the preferential first-line treatment for CL caused by L.aethiopica is intramuscular administration of PM [42].

In Colombia and Belize, CL therapy with PM doses of $18 \mathrm{mg} / \mathrm{kg} /$ day for 14 days or $14 \mathrm{mg} /$ $\mathrm{kg} /$ day for 20 days regimens produced moderate CRs of $50 \%$ and $59 \%$, respectively $[64,65]$. Therefore, various PM formulations were introduced with increased efficacies. In particular, the formulation of PM comprising 15\% PM sulfate with $12 \%$ methylbenzethonium chloride (MBCL) completely cured L. major-related CL in 6-10 days [66]. Likewise, L. major in Israel and L. mexicana in Guatemala were successfully treated with MBCL having CRs of greater than $85 \%[67,68]$. This ointment was $85 \%$ effective in healing patients with L.braziliensis panamensis-related NWCL in Ecuador after 12 months, albeit with some criticism of local stringency after application [27]. Interestingly, CL attributed to L.tropica has largely been identified as a species resistant to PM ointments $[69,70]$. However, current evidence suggests that, despite rarely reported low response incidents, CL treatment with MBCL for more than
6 days seems to be more effective against a wide range of CL infections.

Subsequently, the topical treatment of Bolivian CL caused by L. braziliensis with 15\% PM in aquaphilic base, a complex with a propensity for better adsorption into the lesion, afforded a CR of $77.5 \%$ (31 of 40 patients) in 6 months and was superior to the aquaphilic vehicle negative control [71]. The formulation containing 15\% $\mathrm{PM}$ and $0.5 \%$ gentamicin was able to significantly accelerate the CR of $L$. panamensis CL in Columbia [72]. However, evidence suggests similar CR for both PM and PM-gentamicin in ulcerative $L$. major CL which in turn necessitates further investigations on the use of PM-gentamicin or PM alone [73]. In addition, the formulation containing PM-urea, was $100 \%$ effective against CL due to L.major, with around 30\% relapsed rate [60]. Taken together, CL due to L. major, L. mexicana and L. braziliensis panamensis have been shown to be more susceptible towards PM, although CL caused by L.tropica appears unresponsive to PM-based ointments.

\section{Amphotericin B}

Amphotericin B is commonly used as an alternative drug with a broad spectrum of antiparasitic or antifungal activities to treat patients with leishmaniasis with resistance to antimonials [16]. There are two main types of amphotericin B: amphotericin B deoxycholate and liposomal amphotericin B (L-AmpB, trade name AmBisome) used intralesionally or intravenously as a second-line treatment for CL [10]. Upon binding to ergosterol, the major sterol of the protozoal cell membrane, amphotericin B leads to cell death by promoting ion leakage, pore formation, changes in cell membrane permeability and sudden metabolic shock [74, 75].

Several studies have reported successful treatment of L. major and L. tropica-induced CL with intravenous (11 out of 13 patients cured) or intralesional injection of L-AmpB at a daily dose of $3 \mathrm{mg} / \mathrm{kg}$ for 5 days with an additional dose on the tenth day. Initial infection was gradually re-epithelialized and then disappeared in 8 weeks without abnormalities [24, 76]. 
Furthermore, a recent study validated this treatment regimen to be more responsive than SSG (CR was $85 \%$ vs $70 \%$ for SSG) and recommended as the first-line drug for CL caused by L. braziliensis [77]. AmpB regimen of $3 \mathrm{mg} /$ $\mathrm{kg} /$ day for at least 5 days cured CL infections against L. major and L.aethiopica [24, 78]. However, a weakened Amp-B regimen like $1.5 \mathrm{mg} / \mathrm{kg} /$ day for 5 days was able to show only a CR of 50\% against L. braziliensis [79], which demonstrated the inadequacy of the selected dose. L. mexicana was least sensitive to amphotericin B deoxycholate [80]. Evidence suggests treatment failure or poor responsiveness of AmpB in patients infected with L. infantum, even after treatment with a total dose of $20 \mathrm{mg} /$ $\mathrm{kg}$ or daily $3 \mathrm{mg} / \mathrm{kg}$ for 13 days [81, 82]. Accordingly, the current recommendation is to administer AmpB in doses higher than $1.5 \mathrm{mg} /$ $\mathrm{kg}$ /day for more than 5 days to obtain promising results to treat $C L$ due to L.tropica, L. braziliensis, L. major and L. aethiopica but not for L. infantum.

\section{Pentamidine}

Pentamidine inhibits mitochondrial topoisomerase II, polyamine synthesis, calcium transport, lysin-arginine transport, and eventually impedes the active transport system and mitochondrial membrane potential that leads to parasite death [83]. As per PAHO guidelines, pentamidine is recommended and included in the first line of drugs against CL due to L. guyanensis and L. panamensis [10]. However, except for L. guyanensis, extensive studies on the species-specific responses to pentamidine are rare.

Pentamidine (58.1\%) and MA (55.5\%) were approximately equally effective in treating L. guyanensis-related American tegumentary leishmaniasis (ATL) in Brazil [84]. In a study on L. guyanensis CL, patients given pentamidine isethionate showed $78.8 \%$ CR for single injection $(7 \mathrm{mg} / \mathrm{kg})$, and $83.6 \%$ following two injections; hence, a single treatment at a high dose of $7 \mathrm{mg} / \mathrm{kg}$ has been recommended unless the lesions remain unhealed [85]. Furthermore, in an effort to minimize the number of treatment sessions, a Colombian study on CL revealed that four injections on alternate days of $2 \mathrm{mg}$ pentamidine $/ \mathrm{kg}$ and $3 \mathrm{mg}$ pentamidine $/ \mathrm{kg}$ could give rise to $84 \%$ and $96 \%$ CRs, respectively, with even lesser side effects [86]. It was also found that L.guyanensis treatment with weekly pentamidine at a dose of $7 \mathrm{mg} / \mathrm{kg}$ could result in increasing efficacies with the number of treatment sessions, up to a CR of 96\% [87]. However, the intramuscular administration of pentamidine isethionate tended to fail more than the intravenous administration of pentamidine, in the treatment of CL due to L. guyanensis [31]. The CL therapy for L. braziliensis also showed attractive healing rates with 3-day regimen of $120 \mathrm{mg}$ pentamidine $/ \mathrm{mm}^{2}$ of the lesion as an alternative for $\mathrm{Sb}$ treatment [88], whereas treatment with three doses of $4 \mathrm{mg}$ pentamidine $/ \mathrm{kg} /$ day in 1 week was as effective as antimonials for the treatment of ACL. Furthermore, pentamidine mesylate has been introduced in Suriname as a treatment of CL [89]. As a drawback, some studies report an induction of rhabdomyolysis during CL treatment with pentamidine $[90,91]$. Therefore, to test the effects on the other Leishmania species and to resolve the apparent ambiguities in treatment, more comprehensive studies are warranted to compare the species dependency and treatment regimens of pentamidine.

\section{Azoles}

The azole drugs, including fluconazole, ketoconazole and itraconazole, have been attractive candidates for the treatment of $\mathrm{CL}$ and have been authenticated in vitro, in vivo and also by clinical trials [21, 30, 92, 93], albeit with paradoxical outputs in their efficacies. The global efficacy rates of azoles for L. mexicana, L. infantum, L.donovani, L.major, L. braziliensis and L. tropica were $89 \%, 88 \%, 80 \%, 53 \%, 49 \%$ and $15 \%$, respectively, which implicated a broader variation in species dependency of azole therapy [29]. Interestingly, the growth inhibition observed with itraconazole, fluconazole and ketoconazole against L.donovani and L. braziliensis strains was substantial as opposed to L.aethiopica, L.major, L.tropica or L.m. 
mexicana strains that had lower inhibition [93]. Contradictory results are rife in azole treatment; hence, the dearth of data and the presence of discrepancies in the literature encourage extensive investigations on the antileishmanial activity of azoles, particularly species-specificities, to overcome the current confusions. In a recent study, De Prates et al. excluded the possibility of using fluconazole (at a dose of $6.5-8 \mathrm{mg} / \mathrm{kg} /$ day for 28 days) as an effective regimen for CL due to L. braziliensis [94] and a non-randomized phase 2 trial in the Brazilian Amazon revealed that orally administered fluconazole has no potency in treating L. guyanensis CL [32]. Nonetheless, in Saudi Arabia, 6-week administration of fluconazole was safe and efficient in treating CL due to L. major [95].

Treatment of CL due to L. braziliensis panamensis with ketoconazole showed comparable efficacy to parenteral antimonials, and has been suggested as an initial treatment for CL [30]. Furthermore, L. braziliensis demonstrated substantial in vitro growth inhibition with ketoconazole [93]. Ketoconazole is used to successfully treat L.major-related CL using $400 \mathrm{mg} /$ day dose for 4 weeks [96]. However, the topical treatment though considered more safe is found to be less effective [97]. Even though many studies bear evidence for successful treatment of L. mexicana mexicana with ketoconazole, contradictory outcomes also have been reported with the occurrence of treatment failure $[93,98]$. However, it was proven that L. mexicana was predominantly sensitive to ketoconazole at a dose of $600 \mathrm{mg} /$ day for 4 weeks [21]. Currently, formulations like lipogel, cream and topical gel have been invented that contain different concentrations of ketoconazole; however, in vivo studies have implied meagre antileishmanial activities of these formulations [99] in treating CL caused by L. (Viannia) braziliensis or L. (V.) panamensis [100]. As per the outcomes of in vitro studies and clinical trials that have been performed, ketoconazole can be taken as a reliable treatment against $L$. braziliensis, L. braziliensis panamensis, L. mexicana mexicana and L. mexicana.

Dogra et al. observed promising antileishmanial activity of itraconazole that was based on two studies that demonstrated its effects on patients with CL $[101,102]$, and it was also effective in vivo by treating BALB/c mice subcutaneously inoculated with L.major [103]. Momeni suggested that treatment of CL due to L. major with itraconazole $(7 \mathrm{mg} / \mathrm{kg} / \mathrm{day}$ for 3 weeks) as a single agent may not be fruitful, owing to low response rates [104]. Moreover, supportive evidence emphasizes that response following itraconazole therapy was comparable to that of a placebo in the treatment of $L$. majorassociated CL [105]. Therefore, the usefulness of itraconozole in the treatment of CL due to $L$. major remains doubtful because of inconsistent results shown in various studies. Apart from that, novel azoles, namely voriconazole, 3-imidazolylflavanones, and luliconazole, have brought about prominent repression of both promastigotes and amastigotes of $L$. major in CL treatment in vitro or in vivo $[92,106,107]$.

\section{Cryotherapy}

Cryotherapy involves exposing the lesions to extreme temperatures like $-196{ }^{\circ} \mathrm{C}$, using cryogens like liquid $\mathrm{N}_{2}$ or $\mathrm{CO}_{2}$, which facilitates the destruction of infected tissues. Although painful, cryotherapy does not cause adverse systemic side effects compared to other drugs. It is a simple, inexpensive and rapid procedure that is devoid of the need for local anaesthesia. A number of studies provide evidence for satisfactory cosmetic results and lower relapse rates associated with cryotherapy $[17,108]$, with only a minority of cases reporting burning and possibility of secondary infections after treatment [17].

Studies suggest thermosensitiveness of L. braziliensis, L. tropica, L. infantum and L.aethiopica, indicating cryotherapy as a promising option for CL treatment [109]. However, according to Soto et al., cryotherapy resulted in unfavourable treatment outcomes against single CL lesions caused by L. braziliensis [110]. Cutaneous leishmaniasis due to L. major showed nearly $84 \%$ healing rate in $1-4$ treatment sessions with liquid $\mathrm{N}_{2}$ and the rest of the lesions were cured with an additional 1-3 sessions, leaving negligible scarring and no relapses. However, the physical location and the 
lesion size severely affected the treatment response (lesions smaller than $1 \mathrm{~cm}$ giving the better results) [17]. Cryotherapy given fortnightly was successful in treating CL caused by L. donovani in Sri Lanka, with ulceration, depigmentation and scarring post-treatment, and in Ethiopia, L. aethiopica was treated with an efficiency similar to SSG [111, 112]. In addition, a meta-analysis based on clinical trials affirmed that the overall efficacy of cryotherapy is similar to that of antimonials for the treatment of genus Leishmania [113] and therefore one can exclude the notion of species-specific response fluctuations. Overall, cryotherapy seems to be effective against a wide variety of CL infections caused by mostly OWCL species, whereas the number of previous studies on NWCL remains very few.

\section{Thermotherapy}

Thermotherapy is a cost-effective and uncomplicated method that is used to treat CL in fewer treatment sessions with minimal side effects and scarring, and immensely useful for medically austere areas $[114,115]$. The few minor complications associated with this method are superficial burns (which heals without scarring) and the need for local anaesthesia when thermotherapy is applied with certain devices [18].

Previous studies have evaluated and shown that thermotherapy as a treatment for CL is safe and efficacious, which could produce better outcomes [18]. Berman et al., and Sacks et al., demonstrated the potential for thermotherapy in hampering the multiplication of Leishmania parasites using temperatures greater than $39^{\circ} \mathrm{C}$ $[116,117]$. The underlying mechanism is believed to be both physical damage and immunological destruction of parasites $[118,119]$. More importantly, the authors observed the incontestable elimination of L.tropica parasites from the macrophages at $39^{\circ} \mathrm{C}$, compared to the low response seen in L. donovani parasites [116]. Response to thermotherapy in L. donovani CL in Sri Lanka was very encouraging with increasing responsiveness observed with longer periods of follow-up $(46.5 \%, 56.5 \%$ and $65.9 \%$ CRs in 8,10 and
12 months, respectively) when it was compared with conventional SSG treatment tested in a randomized controlled clinical trial [114]. Furthermore, thermotherapy has been effective in treating CL lesions which have failed treatment with antimonials [18]. Similarly, thermotherapy was efficacious for CL in Iran (CR 80.7\%) with marked superiority over intralesional antimonials (CR 55.3\%) [120]. A comparative study between thermotherapy and intravenous antimonials against $L$. major revealed elevated $\mathrm{CR}$ with thermotherapy with lesser side effects [53]. Also, localized thermotherapy at $50{ }^{\circ} \mathrm{C}$ for $30 \mathrm{~s}$ was more effective than SSG in CL due to L. major [48]. Likewise, a study in Guatemala revealed similar efficacies (73\%) with both thermotherapy and antimony therapy, against L. braziliensis and L. mexicana [121]. In Colombia, no significant difference was reported between efficacies of thermotherapy and miltefosine in patients with $\mathrm{CL}$ caused by L. (V.) panamensis and L. (V.) braziliensis [122]. A single application of thermotherapy gave satisfactory outcome with approximately $69.4 \%$ efficacy (SSG, 75.3\%) in L. tropica CL in Afghanistan [45]. Apart from that, single localized thermotherapy for 5 days was more effective (CR $82.5 \%$ ) for CL caused by L.tropica than intralesional treatment with glucantime for 5 days (CR 74\%) [115]. Thermotherapy could produce better response upon exposure of CL lesion to $52 \pm 2{ }^{\circ} \mathrm{C}$ for 3 min per day for 7 days, especially with the patients infected with L. (V.) peruviana, L. (V.) guyanensis or L. (V.) braziliensis that had reported relapsing after prior antimonial treatments [123]. More importantly, thermotherapy given by a current field-radio frequency (LCF-RF) device resulted in $90 \%$ healing rate at 8 weeks post treatment, in Mexico [124]. The heat therapy has shown promising results as a CL treatment that is comparable to antimonial therapy [119], and warrants further pragmatic trials and inclusion in treatment guidelines as a first-line or an alternative therapy depending on the various reported CRs. The application of thermotherapy has been increasing as a form of treatment for patients with CL due to a wide array of Leishmania parasites of both OWCL and NWCL. Since the temperature effect is more effectual as 
a physical means of cell disruption, thermotherapy has been recommended as an alternative for CL cases with treatment failure [18].

\section{COMBINATION OF TREATMENT METHODS}

Many studies emphasise that combination therapy not only results in increased efficacy in treating CL but also reduces the dose of each drug, adverse side effects, duration, and the risk of emergence of drug resistance [109, 125-127]. Hence, the combination therapy is of great importance. Glucantime with allopurinol was suggested as a suitable drug combination for the treatment of CL due to $L$. tropica and resulted in comparatively better efficacy compared to glucantime or allopurinol alone [128]. Also, allopurinol (20 mg/kg/day) plus MA (30 mg/kg/day) was more effective over high dose of just allopurinol (60 mg/kg/day) against L. major [125]. L. braziliensis panamensis-infected patients with CL showed increased CRs once they were treated with SSG and allopurinol combination (CR 71\%) than that of stibogluconate alone (CR, 39\%) [129]. In L.tropica treatment, when antimony was injected at a dose of $8 \mathrm{mg} / \mathrm{kg} /$ day combined with orally administered allopurinol, the efficacy was higher than that of antimony alone [128]. Similarly, the combination of allopurinol and MA increased the leishmanicidal effects of antimoniate [125]. Hence, the combination of antimonials with allopurinol seems to be more productive in treating CL with high efficacy and low side effects. The mechanism of action of allopurinol is still under investigation with some studies suggesting its involvement in purine metabolism, RNA and protein synthesis [130].

Likewise, a significant increase in the CR of patients with CL was detected when treated with MA plus cryotherapy compared to patients treated with meglumine or cryotherapy alone $[109,131]$. As demonstrated by El-Sayed et al., intralesional administration of SSG in combination with intramuscularly administered SSG or orally administered ketoconazole resulted in over $90 \% \mathrm{CR}$ in CL treatment compared to lesser efficacy by single therapy [132]. With respect to the species-specificities, CL associated with $L$. donovani or L. infantum responds better to combination treatment of antimonials and cryotherapy [133]. In northern Afghanistan, the intralesional treatment of L. major with antimonials with or without cryotherapy was successful; however, around $20 \%$ of patients required miltefosine as a secondary treatment [134]. In Iran, the combination therapy is recommended for CL cases commonly caused by L. tropica or L.major which were efficiently cured by cryotherapy with MA or SSG [127]. Further, Glucantime with 50\% trichloroacetic acid or carbon dioxide laser treatment generated promising results [135]. Cutaneous leishmaniasis due to L. braziliensis in Bolivia gave a CR of 92\% (46 patients out of 50) once treated by miltefosine and intralesional pentamidine combination therapy. There was an increment of CL-related antileishmanial activity of MA after combination with oxiranes [126]. However, a recent in vitro study elucidated the possibility of emerging resistance in L. donovani against drug combinations like miltefosine plus PM and Sb(III) plus PM [136], For diffuse CL, 60 days' treatment regimen of pentavalent $20 \mathrm{mg}$ antimonial/kg plus $15 \mathrm{mg} \mathrm{PM} / \mathrm{kg}$ was superior for L. aethiopica CL, over their respective monotherapies [42]. Collectively, L. donovani, L. tropica, L. major and L. infantum can be successfully treated with antimonial plus cryotherapy. Combination of antimonial with allopurinol is effective for CL due to $L$. tropica, L. braziliensis panamensis and L. major with lesser side effects. L. brazilliensis CL is sensitive to miltefosine/pentamidine combination or antimonial/allopurinol combination. However, further investigations are warranted to ensure the proper use of drug combinations with longterm efficacy and the ability to treat a variety of Leishmania species.

\section{CONCLUSIONS}

Broad variations are noted in efficacies of CL treatment methods depending on the Leishmania species, with a possible relationship to the region of endemicity. Antimonial drugs, despite 
treatment failures reported in some instances, appeared to be efficacious in treating a wide array of CL cases, caused by different Leishmania species, all over the world. Miltefosine had a good or rather near-perfect responsiveness as a treatment for a variety of Leishmania species. Formulations of PM including, MBCL, PM-gentamicin and PM-urea were effective against CL caused by a variety of Leishmania species; however, L. tropica was highly resistant to PM. Amphotericin B treatment with $1.5 \mathrm{mg} / \mathrm{kg} /$ day for more than 5 days was an effective regimen for OWCL and NWCL species but probably not for L. infantum. Pentamidine can be recommended for the treatment of CL caused by L. guyanensis and L. braziliensis, but its applicability to other CL species is still under debate. Azoles were the drugs with the most controversial treatment outcomes; however, the availability of a number of azoles has enabled its use in treating several CL species. It is noteworthy that there was a tendency to get better results with azoles against NWCL infections than OWCL. Cryotherapy has shown high efficacy for the treatment of OWCL in a number of studies. However, the efficacies and response parameters of NWCL have to be further established. Thermotherapy was as effective as the antimonial treatment, and should be extensively utilized whenever possible, as the side effects associated are minimal compared to the other CL therapies. More importantly, the heat effect had substantially inhibited several Leishmania species belonging to both OWCL and NWCL and was effective for CL cases with treatment failure to chemotherapy. Combination therapy is more effective for antimonial drugs viz. with cryotherapy, miltefosine, and allopurinol, than using monotherapy of antimonials alone, as the cumulative effect could augment the efficacy of the antimonials. Combinations were more powerful against both OWCL and NWCL cases. Combinations were able to produce a favourable treatment outcome where treatment failure has become a hindrance with respective monotherapies. Furthermore, combination therapy followed by a monotherapy may elevate the efficacy of treatment of CL above that of monotherapy alone. Of all the species, L. major was the most sensitive to almost all the currently available treatment methods with other species showing diverse responses depending on the situation. Treatment failure or unresponsiveness is a limiting factor for effective use of most of the drugs against leishmaniasis. Discovery of new drugs or non-chemotherapeutic treatment methods, recognizing and utilizing already existing drugs that have leishmanicidal effects and using treatment combinations, with a focus on species-specific responses will lead to better treatment outcome and control of leishmaniasis.

\section{ACKNOWLEDGEMENTS}

Funding. NDK is supported by the National Institute of Allergy and Infectious Diseases (NIAID) of the National Institutes of Health (NIH), USA under Award Number U01AI136033. The U.S. Civilian Research \& Development Foundation (CRDF Global) under Award Number DAA3-19-65623 supports HS and NDK. The content is solely the responsibility of the authors and does not necessarily represent the official views of the CRDF Global or the NIH. No funding was received for the publication of this article.

Authorship. All named authors meet the International Committee of Medical Journal Editors (ICMJE) criteria for authorship for this article, take responsibility for the integrity of the work as a whole, and have given their approval for this version to be published.

Author Contributions. Conceptualization: [Rajamanthrilage Kasun Madusanka, Hermali Silva]; Methodology: [Rajamanthrilage Kasun Madusanka, Hermali Silva]; Formal analysis and investigation: [Rajamanthrilage Kasun Madusanka, Hermali Silva]; Writing-original draft preparation: [Rajamanthrilage Kasun Madusanka, Hermali Silva]; Writing - review and editing: [Rajamanthrilage Kasun Madusanka, Hermali Silva, Nadira Karunaweera]; Funding acquisition: [Nadira Karunaweera, Hermali Silva] Supervision: [Nadira Karunaweera]; All 
authors read and approved the final manuscript.

Disclosures. Rajamanthrilage Kasun Madusanka, Hermali Silva, and Nadira D. Karunaweera all have nothing to disclose.

Compliance with Ethics Guidelines. This article is based on previously published work and does not contain novel data or information related to human or animal studies.

Open Access. This article is licensed under a Creative Commons Attribution-NonCommercial 4.0 International License, which permits any non-commercial use, sharing, adaptation, distribution and reproduction in any medium or format, as long as you give appropriate credit to the original author(s) and the source, provide a link to the Creative Commons licence, and indicate if changes were made. The images or other third party material in this article are included in the article's Creative Commons licence, unless indicated otherwise in a credit line to the material. If material is not included in the article's Creative Commons licence and your intended use is not permitted by statutory regulation or exceeds the permitted use, you will need to obtain permission directly from the copyright holder. To view a copy of this licence, visit http://creativecommons.org/licenses/by$\mathrm{nc} / 4.0 /$.

\section{REFERENCES}

1. Killick-Kendrick R. The biology and control of Phlebotomine sand flies. Clin Dermatol. 1999;17(3):279-89.

2. World Health Organization. Control of the leishmaniases: Report of a meeting of the WHO Expert Committee on the Control of Leishmaniases,Geneva, 22-26 March 2010. 2010. https://apps. who.int/iris/handle/10665/44412. Accessed 9 May 2021.

3. Alvar J, Vélez ID, Bern C, et al. Leishmaniasis worldwide and global estimates of its incidence. PLoS One. 2012;7(5):35671.
4. Alvar J, Yactayo S, Bern C. Leishmaniasis and poverty. Trends Parasitol. 2006;22(12):552-7.

5. Burza S, Croft SL, Boelaert M. Leishmaniasis. Lancet. 2018;392(10151):951-70.

6. Kevric I, Cappel MA, Keeling JH. New World and Old World Leishmania infections: a practical review. Dermatol Clin. 2015;33(3):579-93.

7. Reithinger R, Dujardin JC, Louzir H, Pirmez C, Alexander B, Brooker S. Cutaneous leishmaniasis. Lancet Infect Dis. 2007;7(9):581-96.

8. Costa JML, Marsden PD, Llanos-Cuentas EA, et al. Disseminated cutaneous leishmaniasis in a field clinic in Bahia, Brazil: a report of eight cases. J Trop Med Hyg. 1986;89(6):319-23.

9. Carvalho EM, Barral A, Costa JML, Bittencourt A, Marsden P. Clinical and immunopathological aspects of disseminated cutaneous leishmaniasis. Acta Trop. 1994;56(4):315-25. Accessed 9 May 2021.

10. Pan American Health Organization, World Health Organization. Leishmaniasis in the Americas: treatment recommendation. 2015. http://iris.paho. org/xmlui/bitstream/handle/123456789/7704/ 9789275117521_eng.pdf?sequence=5\&isAllowed= y. Accessed 9 May 2021.

11. WHO. Leishmaniasis. https://www.who.int/newsroom/fact-sheets/detail/leishmaniasis. Accessed 9 May 2021.

12. Koff $A B$, Rosen T. Treatment of cutaneous leishmaniasis. J Am Acad Dermatol. 1994;31(5):693-708.

13. Desjeux P. Leishmaniasis: public health aspects and control. Clin Dermatol. 1996;14(5):417-23.

14. Modabber F, Buffet PA, Torreele E, Milon G, Croft SL. Consultative meeting to develop a strategy for treatment of cutaneous leishmaniasis. Institute Pasteur, Paris. 13-15 June, 2006. Kinetoplastid Biol Dis. $2007 ; 6: 3$.

15. Savioli L, Engels D, Daumerie D, et al. Response from Savioli and colleagues from the Department of Neglected Tropical Diseases, World Health Organization. PLoS Med. 2006;3(6):0936-8.

16. Berman JD. Human leishmaniasis: clinical, diagnostic, and chemotherapeutic developments in the last 10 years. Clin Infect Dis. 1997;24(4):684-703.

17. Mosleh IM, Geith E, Natsheh L, Schönian G, Abotteen N, Kharabsheh S. Efficacy of a weekly cryotherapy regimen to treat Leishmania major cutaneous leishmaniasis. J Am Acad Dermatol. 2008;58(4):617-24. 
18. Silva H, Liyanage A, Deerasinghe $\mathrm{T}$, et al. Therapeutic response to thermotherapy in cutaneous leishmaniasis treatment failures for sodium stibogluconate: a randomized controlled proof of principle clinical trial. Am J Trop Med Hyg. 2021;104(3):945-50.

19. Oliveira RM de, Melo S de A, Penha-Silva TA da, Almeida-Souza F, Abreu-Silva AL. Alternative treatment for leishmaniasis. In: Leishmaniases as Reemerging Diseases. InTech; 2018. https://doi.org/ 10.5772/intechopen.75895.

20. Berbert TRN, Mello TFP De, Wolf Nassif P, et al. Pentavalent antimonials combined with other therapeutic alternatives for the treatment of cutaneous and mucocutaneous leishmaniasis: a systematic review. Dermatol Res Pract. 2018;2018: 9014726 .

21. Navin TR, Arana BA, Arana FE, Berman JD, Chajón JF. Placebo-controlled clinical trial of sodium stibogluconate (Pentostam) versus ketoconazole for treating cutaneous leishmaniasis in Guatemala. J Infect Dis. 1992;165(3):528-34.

22. Arevalo J, Ramirez L, Adaui V, et al. Influence of Leishmania (Viannia) species on the response to antimonial treatment in patients with American tegumentary leishmaniasis. J Infect Dis. 2007;195(12):1846-51.

23. Sundar S, Jaya J. Liposomal amphotericin B and leishmaniasis: dose and response. J Glob Infect Dis. 2010;2(2):159.

24. Ono $\mathrm{M}$, Takahashi $\mathrm{K}$, Taira $\mathrm{K}$, Uezato $\mathrm{H}$, Takamura $\mathrm{S}$, Izaki S. Cutaneous leishmaniasis in a Japanese returnee from West Africa successfully treated with liposomal amphotericin B. J Dermatol. 2011;38(11): 1062-5.

25. Tahir M, Bashir U, Hafeez J, Ghafoor R. Safety and efficacy of miltefosine in cutaneous leishmaniasis: an open label, non-comparative study from Balochistan. Pak J Med Sci. 2019;35(2):495-9.

26. Soto J, Arana BA, Tolado J, et al. Miltefosine for new world cutaneous leishmaniasis. Clin Infect Dis. 2004;38(9):1266-72.

27. Krause G, Kroeger A. Topical treatment of American cutaneous leishmaniasis with paramomycin and methylbenzethonium chloride: a clinical study under field conditions in Ecuador. Trans R Soc Trop Med Hyg. 1994;88(1):92-4.

28. Asilian A, Davami M. Comparison between the efficacy of photodynamic therapy and topical paromomycin in the treatment of Old World cutaneous leishmaniasis: a placebo-controlled, randomized clinical trial. Clin Exp Dermatol. 2006;31(5):634-7.

29. Galvão EL, Rabello A, Cota GF. Efficacy of azole therapy for tegumentary leishmaniasis: a systematic review and meta-analysis. PLoS One. 2017;12(10): e0186117.

30. Saenz RE, Paz H, Berman JD. Efficacy of ketoconazole against Leishmania braziliensis panamensis cutaneous leishmaniasis. Am J Med. 1990;89(2): 147-55.

31. Christen JR, Bourreau E, Demar M, et al. Use of the intramuscular route to administer pentamidine isethionate in Leishmania guyanensis cutaneous leishmaniasis increases the risk of treatment failure. Travel Med Infect Dis. 2018;24:31-6.

32. Francesconi VA, Francesconi F, Ramasawmy R, Romero GAS, Alecrim MGC. Failure of fluconazole in treating cutaneous leishmaniasis caused by Leishmania guyanensis in the Brazilian Amazon: an open, nonrandomized phase 2 trial. PLoS Negl Trop Dis. 2018;12(2):e0006225.

33. Oliveira LF, Schubach AO, Martins MM, et al. Systematic review of the adverse effects of cutaneous leishmaniasis treatment in the New World. Acta Trop. 2011;118(2):87-96.

34. Mandal G, Mandal S, Sharma M, et al. Speciesspecific antimonial sensitivity in Leishmania is driven by post-transcriptional regulation of AQP1. PLoS Negl Trop Dis. 2015;9(2):e0003500.

35. Krauth-Siegel RL, Comini MA. Redox control in trypanosomatids, parasitic protozoa with trypanothione-based thiol metabolism. Biochim Biophys Acta. 2008;1780(11):1236-48.

36. Chakraborty AK, Majumder HK. Mode of action of pentavalent antimonials: specific inhibition of type I DNA topoisomerase of Leishmania donovani. Biochem Biophys Res Commun. 1988;152(2):605-11.

37. Walker J, Saravia NG. Inhibition of Leishmania donovani promastigote DNA topoisomerase I and human monocyte DNA topoisomerases I and II by antimonial drugs and classical antitopoisomerase agents. J Parasitol. 2004;90(5):1155-62.

38. Berman JD, Waddel D, Hanson BD. Biochemical mechanisms of the antileishmanial activity of sodium stibogluconate. Antimicrob Agents Chemother. 1985;27(6):916-20.

39. Herman JD, Gallalee JV, Best JM. Sodium stibogluconate (Pentostam) inhibition of glucose catabolism via the glycolytic pathway, and fatty acid $\beta$ oxidation in Leishmania mexicana amastigotes. Biochem Pharmacol. 1987;36(2):197-201. 
40. Decuypere S, Vanaerschot $\mathrm{M}$, Brunker $\mathrm{K}$, et al. Molecular mechanisms of drug resistance in natural Leishmania populations vary with genetic background. PLoS Negl Trop Dis. 2012;6(2):e1514.

41. Romero GAS, De Farias GMV, Paes MG, De Oliveira MV. Comparison of cutaneous leishmaniasis due to Leishmania (Viannia) braziliensis and L. (V) guyanensis in Brazil: therapeutic response to meglumine antimoniate. Am J Trop Med Hyg. 2001;65(5): 456-65.

42. van Griensven J, Gadisa E, Aseffa A, Hailu A, Beshah AM, Diro E. Treatment of cutaneous leishmaniasis caused by Leishmania aethiopica: a systematic review. PLoS Negl Trop Dis. 2016;10(3):e0004495.

43. Neal RA, Allen S, Mccoy N, Olliaro P, Croft SL. The sensitivity of Leishmania species to aminosidine. J Antimicrob Chemother. 1995;35(5):577-84.

44. Sarkar A, Ghosh S, Pakrashi S, Roy D, Sen S, Chatterjee M. Leishmania strains causing self-healing cutaneous leishmaniasis have greater susceptibility towards oxidative stress. Free Radic Res. 2012;46(5): 665-73.

45. Reithinger R, Mohsen M, Wahid M, et al. Efficacy of thermotherapy to treat cutaneous leishmaniasis caused by Leishmania tropica in Kabul, Afghanistan: a randomized, controlled trial. Clin Infect Dis. 2005;40(8):1148-55.

46. Wortmann G, Miller RS, Oster C, Jackson J, Aronson $\mathrm{N}$. A randomized, double-blind study of the efficacy of a 10- or 20-day course of sodium stibogluconate for treatment of cutaneous leishmaniasis in United States military personnel. Clin Infect Dis. 2002;35(3):261-7.

47. Arana BA, Navin TR, Arana FE, Berman JD, Rosenkaimer F. Efficacy of a short course (10 days) of high-dose meglumine antimonate with or without interferon-gamma in treating cutaneous leishmaniasis in Guatemala. Clin Infect Dis. 1994;18(3): 381-4.

48. Aronson NE, Wortmann GW, Byrne WR, et al. A randomized controlled trial of local heat therapy versus intravenous sodium stibogluconate for the treatment of cutaneous Leishmania major infection. PLoS Negl Trop Dis. 2010;4(3):e628.

49. Ballou WR, Gordon DM, Andujar J, et al. Safety and efficacy of high-dose sodium stibogluconate therapy of American cutaneous leishmaniasis. Lancet. 1987;330(8549):13-6.

50. Sindermann H, Krasovec M, Burg G. Topical administration of hexadecylphosphocholine in patients with cutaneous lymphomas: results of a phase I/II study. J Am Acad Dermatol. 1993;29(6): 963-70.

51. Sindermann H, Croft SL, Engel KR, et al. Miltefosine (Impavido): the first oral treatment against leishmaniasis. Med Microbiol Immunol. 2004;193(4): 173-80.

52. Zerpa O, Ulrich M, Blanco B, et al. Diffuse cutaneous leishmaniasis responds to miltefosine but then relapses. Br J Dermatol. 2007;156(6):1328-35.

53. Monge-Maillo B, López-Vélez R. Therapeutic options for old world cutaneous leishmaniasis and new world cutaneous and mucocutaneous leishmaniasis. Drugs. 2013;73(17):1889-920.

54. Soto J, Toledo J, Gutierrez P, et al. Treatment of American cutaneous leishmaniasis with miltefosine, an oral agent. Clin Infect Dis. 2001;33(7):E5761.

55. Machado PR, Ampuero J, Guimarães LH, et al. Miltefosine in the treatment of cutaneous leishmaniasis caused by leishmania braziliensis in Brazil: a randomized and controlled trial. PLoS Negl Trop Dis. 2010;4(12):1-6.

56. Chrusciak-Talhari A, Dietze R, Talhari CC, et al. Randomized controlled clinical trial to access efficacy and safety of miltefosine in the treatment of cutaneous leishmaniasis caused by Leishmania (Viannia) guyanensis in Manaus, Brazil. Am J Trop Med Hyg. 2011;84(2):255-60.

57. Soto J, Tolado J, Valda L, et al. Treatment of Bolivian mucosal leishmaniasis with miltefosine. Clin Infect Dis. 2007;44(3):350-6.

58. Mohebali M, Fotouhi A, Hooshmand B, et al. Comparison of miltefosine and meglumine antimoniate for the treatment of zoonotic cutaneous leishmaniasis (ZCL) by a randomized clinical trial in Iran. Acta Trop. 2007;103(1):33-40.

59. Asilian A, Jalayer $T$, Nilforooshzadeh $M$, et al. Treatment of cutaneous leishmaniasis with aminosidine (paromomycin) ointment: double-blind, randomized trial in the Islamic Republic of Iran. Bull World Health Organ. 2003;81(5):353-9.

60. Grogl M, Schuster BG, Ellis WY, Berman JD. Successful topical treatment of murine cutaneous leishmaniasis with a combination of paromomycin (aminosidine) and gentamicin. J Parasitol. 1999;85(2):354-9.

61. Fernández MM, Malchiodi EL, Algranati ID. Differential effects of paromomycin on ribosomes of Leishmania Mexicana and mammalian cells. Antimicrob Agents Chemother. 2011;55(1):86-93. 
62. Chawla B, Jhingran A, Panigrahi A, Stuart KD, Madhubala R. Paromomycin affects translation and vesicle-mediated trafficking as revealed by proteomics of paromomycin-susceptible-resistant Leishmania donovani. PLoS One. 2011;6(10):e26660.

63. World Health Organization. Cutaneous and Mucosal Leishmaniasis Pan American Health Organization. WHO Pan American Health Organization. $2020 . \quad$ https://www.paho.org/en/topics/ leishmaniasis/cutaneous-and-mucosal-

leishmaniasis. Accessed 10 Jun 2021.

64. Soto J, Grog M, Berman J, Olliaro P. Limited efficacy of injectable aminosidine as single-agent therapy for Colombian cutaneous leishmaniasis. Trans R Soc Trop Med Hyg. 1994;88(6):695-8.

65. Hepburn NC, Tidman MJ, Hunter JAA. Aminosidine (paromomycin) versus sodium stibogluconate for the treatment of American cutaneous leishmaniasis. Trans R Soc Trop Med Hyg. 1994;88(6):700-3.

66. El-On J, Even-Paz Z, Livshin R, Weinrauch L, Jacobs GP. Topical treatment of recurrent cutaneous leishmaniasis with ointment containing paromomycin and methylbenzethonium chloride. $\mathrm{Br}$ Med J (Clin Res Ed). 1985;291(6497):704-5.

67. Arana BA, Mendoza CE, Rizzo NR, Kroeger A. Randomized, controlled, double-blind trial of topical treatment of cutaneous leishmaniasis with paromomycin plus methylbenzethonium chloride ointment in Guatemala. Am J Trop Med Hyg. 2001;65(5):466-70.

68. El-On J, Halevy S, Grunwald MH, Weinrauch L. Topical treatment of Old World cutaneous leishmaniasis caused by Leishmania major: a doubleblind control study. J Am Acad Dermatol. 1992;27(2):227-31.

69. Ozgoztasi O, Baydar I. A randomized clinical trial of topical paromomycin versus oral ketoconazole for treating cutaneous leishmaniasis in Turkey. Int J Dermatol. 1997;36(1):61-3.

70. Shani-Adir A, Kamil S, Rozenman D, et al. Leishmania tropica in northern Israel: a clinical overview of an emerging focus. J Am Acad Dermatol. 2005;53(5):810-5.

71. Soto J, Soto P, Ajata A, et al. Topical 15\% paromomycin-aquaphilic for Bolivian Leishmania braziliensis cutaneous leishmaniasis: a randomized, placebo-controlled trial. Clin Infect Dis. 2019;68(5): 844-9.

72. Soto JM, Toledo JT, Gutierrez P, et al. Treatment of cutaneous leishmaniasis with a topical antileishhmanial drug (WR279396): phase 2 pilot study. Am J Trop Med Hyg. 2002;66(2):147-51.
73. Ben Salah A, Ben Messaoud N, Guedri E, et al. Topical paromomycin with or without gentamicin for cutaneous leishmaniasis. $\mathrm{N}$ Engl J Med. 2013;368(6):524-32.

74. Coukell AJ, Brogden RN. Liposomal amphotericin B: therapeutic use in the management of fungal infections and visceral leishmaniasis. Drugs. 1998;55(4):585-612.

75. Shirzadi MR. Lipsosomal amphotericin B: a review of its properties, function, and use for treatment of cutaneous leishmaniasis. Res Rep Trop Med. 2019;10:11-8.

76. Solomon M, Pavlotsky F, Leshem E, Ephros M, Trau $\mathrm{H}$, Schwartz E. Liposomal amphotericin B treatment of cutaneous leishmaniasis due to Leishmania tropica. J Eur Acad Dermatol Venereol. 2011;25(8): 973-7.

77. Solomon M, Pavlotzky F, Barzilai A, Schwartz E. Liposomal amphotericin B in comparison to sodium stibogluconate for Leishmania braziliensis cutaneous leishmaniasis in travelers. J Am Acad Dermatol. 2013;68(2):284-9.

78. Zanger P, Kötter I, Raible A, Gelanew T, Schönian G, Kremsner PG. Case report: successful treatment of cutaneous leishmaniasis caused by Leishmania aethiopica with liposomal amphothericin B in an immunocompromised traveler returning from Eritrea. Am J Trop Med Hyg. 2011;84(5):692-4.

79. Motta JOC, Sampaio RNR. A pilot study comparing low-dose liposomal amphotericin B with $\mathrm{N}$-methyl glucamine for the treatment of American cutaneous leishmaniasis. J Eur Acad Dermatol Venereol. 2012;26(3):331-5.

80. Escobar P, Matu S, Marques C, Croft SL. Sensitivities of Leishmania species to hexadecylphosphocholine (miltefosine), ET-18-OCH3 (edelfosine) and amphotericin B. Acta Trop. 2002;81(2):151-7.

81. Hervás JA, Martín-Santiago A, Hervás D, et al. Old world: Leishmania infantum cutaneous leishmaniasis unresponsive to liposomal amphotericin B treated with topical imiquimod. Pediatr Infect Dis J. 2012;31(1):97-100.

82. Guery R, Henry B, Martin-Blondel G, et al. Liposomal amphotericin $B$ in travelers with cutaneous and muco-cutaneous leishmaniasis: not a panacea. PLoS Negl Trop Dis. 2017;11(11):e0006094.

83. Basselin M, Lawrence F, Robert-Gero M. Pentamidine uptake in Leishmania donovani and Leishmania amazonensis promastigotes and axenic amastigotes. Biochem J. 1996;315(2):631-4. 
84. Neves LO, Talhari AC, Gadelha EPN, et al. Estudo clínico randomizado comparando antimoniato de meglumina, pentamidina e anfotericina $\mathrm{B}$ para $\mathrm{o}$ tratamento da leishmaniose cutânea ocasionada por Leishmania guyanensis. An Bras Dermatol. 2011;86(6):1092-101.

85. Roussel M, Nacher M, Frémont G, et al. Comparison between one and two injections of pentamidine isethionate, at $7 \mathrm{mg} / \mathrm{kg}$ in each injection, in the treatment of cutaneous leishmaniasis in French Guiana. Ann Trop Med Parasitol. 2006;100(4): 307-14.

86. Soto J, Buffet P, Grogl M, Berman J. Successful treatment of Colombian cutaneous leishmaniasis with four injections of pentamidine. Am J Trop Med Hyg. 1994;50(1):107-11.

87. Gadelha EPN, Ramasawmy R, da Costa OB, et al. An open label randomized clinical trial comparing the safety and effectiveness of one, two or three weekly pentamidine isethionate doses (seven milligrams per kilogram) in the treatment of cutaneous leishmaniasis in the Amazon Region. PLoS Negl Trop Dis. 2018;12(10):e0006850.

88. Soto J, Paz D, Rivero D, et al. Intralesional pentamidine: a novel therapy for single lesions of Bolivian cutaneous leishmaniasis. Am J Trop Med Hyg. 2016;94(4):852-6.

89. Lai A Fat EJSK, Vrede MA, Soetosenojo RM, Lai A Fat RFM. Pentamidine, the drug of choice for the treatment of cutaneous leishmaniasis in Surinam. Int J Dermatol. 2002;41(11):796-800.

90. Delobel P, Pradinaud R. Rhabdomyolysis associated with pentamidine isethionate therapy for American cutaneous leishmaniasis. J Antimicrob Chemother. 2003;51(5):1319-20.

91. Lieber-Mbomeyo A, Lipsker D, Miléa M, Heid E. Rhabdomyolyse induite par l'iséthionate de pentamidine (Pentacarinat $\left.{ }^{\circledR}\right)$ lors du traitement d'une leishmaniose cutanée: 2 cas. Ann Dermatol Venereol. 2002;129(1):50-2.

92. Shokri A, Emami S, Fakhar M, Teshnizi SH, Keighobadi M. In vitro antileishmanial activity of novel azoles (3-imidazolylflavanones) against promastigote and amastigote stages of Leishmania major. Acta Trop. 2017;167:73-8.

93. Beach DH, Goad LJ, Holz GG. Effects of antimycotic azoles on growth and sterol biosynthesis of Leishmania promastigotes. Mol Biochem Parasitol. 1988;31(2):149-62.

94. De Prates FVO, Dourado MEF, Silva SC, et al. Fluconazole in the treatment of cutaneous leishmaniasis caused by Leishmania braziliensis: a randomized controlled trial. Clin Infect Dis. 2017;64(1):67-71.

95. Alrajhi AA, Ibrahim EA, De Vol EB, Khairat M, Faris RM, Maguire JH. Fluconazole for the treatment of cutaneous leishmaniasis caused by Leishmania major. N Engl J Med. 2002;346(12):891-5.

96. Weinrauch L, Livshin R, Even-Paz Z, El-On J. Efficacy of ketoconazole in cutaneous leishmaniasis. Arch Dermatol Res. 1983;275(5):353-4.

97. Abahusein A, Larbi EB, Al-Khawajah A, Al-Gindan $\mathrm{Y}$, Jain S. Evaluation of topical ketoconazole in cutaneous leishmaniasis. East Afr Med J. 1992;69(1): 14-7.

98. Baum KF, Berens RL. Successful treatment of cutaneous leishmaniasis with allopurinol after failure of treatment with ketoconazole. Clin Infect Dis. 1994;18(5):813-5.

99. Momeni AZ, Aminjavaheri M, Omidghaemi MR. Treatment of cutaneous leishmaniasis with ketoconazole cream. J Dermatolog Treat. 2003;14(1): 26-9.

100. Vera AM, Casadiego OA, Mantilla JC, Escobar P. Evaluation of ketoconazole formulations for topical use in cutaneous leishmaniasis caused by Leishmania (Viannia). Rev Peru Med Exp Salud Publica. 2018;35(3):476-82.

101. Dogra J, Saxena VN. Itraconazole and leishmaniasis: a randomised double-blind trial in cutaneous disease. Int J Parasitol. 1996;26(12):1413-5.

102. Dogra J, Aneja N, Lal BB, Mishra SN. Cutaneous leishmaniasis in India: clinical experience with itraconazole (R51 211 Janssen). Int J Dermatol. 1990;29(9):661-2.

103. Zakai A, Zimmo H. Effects of itraconazole and terbinafine on Leishmania major lesions in BALB/C mice. Ann Trop Med Parasitol. 2000;94(8):787-91.

104. Momeni AZ. Treatment of cutaneous leishmaniasis with itraconazole. Arch Dermatol. 1996;132(7):784.

105. Nassiri-Kashani M, Firooz A, Khamesipour A, et al. A randomized, double-blind, placebo-controlled clinical trial of itraconazole in the treatment of cutaneous leishmaniasis. J Eur Acad Dermatol Venereol. 2005;19(1):80-3.

106. Oryan A, Bahrami S, Bemani E. Efficacy of voriconazole on leishmaniasis by Leishmania major: an in vitro and in vivo study. Asian Pac J Trop Med. 2018;11(10):562-9. 
107. Shokri A, Abastabar M, Keighobadi $M$, et al. Promising antileishmanial activity of novel imidazole antifungal drug luliconazole against Leishmania major: in vitro and in silico studies. J Glob Antimicrob Resist. 2018;14:260-5.

108. Panagiotopoulos A, Stavropoulos PG, Hasapi V, Papakonstantinou AM, Petridis A, Katsambas A. Treatment of cutaneous leishmaniasis with cryosurgery. Int J Dermatol. 2005;44(9):749-52.

109. Asilian A, Sadeghinia A, Faghihi G, Momeni A. Comparative study of the efficacy of combined cryotherapy and intralesional meglumine antimoniate (Glucantime ${ }^{\circledR}$ ) vs. cryotherapy and intralesional meglumine antimoniate (Glucantime ${ }^{\circledR}$ ) alone for the treatment of cutaneous leishmaniasis. Int J Dermatol. 2004;43(4):281-3.

110. Soto J, Rojas E, Guzman M, et al. Intralesional antimony for single lesions of Bolivian cutaneous Leishmaniasis. Clin Infect Dis. 2013;56(9):1255-60.

111. Negera E, Gadisa E, Hussein J, et al. Treatment response of cutaneous leishmaniasis due to Leishmania aethiopica to cryotherapy and generic sodium stibogluconate from patients in Silti, Ethiopia. Trans R Soc Trop Med Hyg. 2012;106(8):496-503.

112. Ranawaka RR, Weerakoon HS, Opathella N. Liquid nitrogen cryotherapy on Leishmania donovani cutaneous leishmaniasis. J Dermatol Treat. 2011;22(4): 241-5.

113. López-Carvajal L, Cardona-Arias JA, Zapata-Cardona MI, Sánchez-Giraldo V, Vélez ID. Efficacy of cryotherapy for the treatment of cutaneous leishmaniasis: meta-analyses of clinical trials. BMC Infect Dis. 2016;16:360.

114. Refai WF, Madarasingha NP, Sumanasena B, et al. Efficacy, safety and cost-effectiveness of thermotherapy in the treatment of Leishmania donovaniinduced cutaneous leishmaniasis: a randomized controlled clinical trial. Am J Trop Med Hyg. 2017;97(4):1120-6.

115. Safi N, Davis GD, Nadir M, Hamid H, Robert LL, Case AJ. Evaluation of thermotherapy for the treatment of cutaneous leishmaniasis in Kabul, Afghanistan: a randomized controlled trial. Mil Med. 2012;177(3):345-51.

116. Berman JD, Neva FA. Effect of temperature on multiplication of Leishmania amastigotes within human monocyte-derived macrophages in vitro. Am J Trop Med Hyg. 1981;30(2):318-21.

117. Sacks DL, Barral A, Neva FA. Thermosensitivity patterns of Old vs. New World cutaneous strains of Leishmania growing within mouse peritoneal macrophages in vitro. Am J Trop Med Hyg. 1983;32(2):300-4.

118. Lakhal-Naouar I, Slike BM, Aronson NE, Marovich MA. The immunology of a healing response in cutaneous leishmaniasis treated with localized heat or systemic antimonial therapy. PLoS Negl Trop Dis. 2015;9(10):e0004178. https://doi.org/10.1371/ journal.pntd.0004178.

119. Siadat A, Iraji F, Zolfaghari A, Shariat S, Jazi S. Heat therapy for cutaneous leishmaniasis: a literature review. J Res Med Sci. 2021;26(1):15.

120. Sadeghian G, Nilfroushzadeh MA, Iraji F. Efficacy of local heat therapy by radiofrequency in the treatment of cutaneous leishmaniasis, compared with intralesional injection of meglumine antimoniate. Clin Exp Dermatol. 2007;32(4):371-4.

121. Navin TR, Arana BA, Arana FE, De Merida AM, Castillo AL, Pozuelos JL. Placebo-controlled clinical trial of meglumine antimonate (Glucantime) vs. localized controlled heat in the treatment of cutaneous leishmaniasis in Guatemala. Am J Trop Med Hyg. 1990;42(1):43-50.

122. López L, Cruz C, Godoy G, Robledo SM, Vélez ID. Termoterapia efectiva y más segura que la miltefosina en el tratamiento de la leishmaniasis cutánea en Colombia. Rev Inst Med Trop Sao Paulo. 2013;55(3):197-204.

123. Valencia BM, Miller D, Witzig RS, Boggild AK, Llanos-Cuentas A. Novel low-cost thermotherapy for cutaneous leishmaniasis in Peru. PLoS Negl Trop Dis. 2013;7(5):e2196.

124. Velasco-Castrejon O, Walton BC, Rivas-Sanchez B, et al. Treatment of cutaneous leishmaniasis with localized current field (radio frequency) in Tabasco, Mexico. Am J Trop Med Hyg. 1997;57(3):309-12.

125. Momeni AZ, Reiszadae MR, Aminjavaheri M. Treatment of cutaneous leishmaniasis with a combination of allopurinol and low-dose meglumine antimoniate. Int J Dermatol. 2002;41(7):441-3.

126. Gonçalves-Oliveira LF, Souza-Silva F, de Castro Côrtes LM, et al. The combination therapy of meglumine antimoniate and oxiranes (epoxy- $\alpha$-lapachone and epoxymethyl-lawsone) enhance the leishmanicidal effect in mice infected by Leishmania (Leishmania) amazonensis. Int J Parasitol Drugs Drug Resist. 2019;10:101-8.

127. Asilian A, Sadeghinia A, Faghihi G, Momeni A, Amini HA. The efficacy of treatment with intralesional meglumine antimoniate alone, compared with that of cryotherapy combined with the meglumine antimoniate or intralesional sodium stibogluconate, in the treatment of cutaneous 
leishmaniasis. Ann Trop Med Parasitol. 2003;97(5): 493-8.

128. Esfandiarpour I, Alavi A. Evaluating the efficacy of allopurinol and meglumine antimoniate (Glucantime) in the treatment of cutaneous leishmaniasis. Int J Dermatol. 2002;41(8):521-4.

129. Martinez S, Gonzalez M, Vernaza ME. Treatment of cutaneous leishmaniasis with allopurinol and stibogluconate. Clin Infect Dis. 1997;24(2):165-9.

130. Olliaro PL, Bryceson ADM. Practical progress and new drugs for changing patterns of leishmaniasis. Parasitol Today. 1993;9(9):323-8.

131. Salmanpour R, Razmavar MR, Abtahi N. Comparison of intralesional meglumine antimoniate, cryotherapy and their combination in the treatment of cutaneous leishmaniasis. Int J Dermatol. 2006;45(9):1115-6.

132. El-Sayed M, Anwar A. Intralesional sodium stibogluconate alone or its combination with either intramuscular sodium stibogluconate or oral ketoconazole in the treatment of localized cutaneous leishmaniasis: a comparative study. J Eur Acad Dermatol Venereol. 2010;24(3):335-40.

133. Hodiamont CJ, Kager PA, Bart A, et al. Species-directed therapy for leishmaniasis in returning travellers: a comprehensive guide. PLoS Negl Trop Dis. 2014;8(5):e2832.

134. Van Thiel PP, Leenstra T, De Vries HJ, et al. Cutaneous leishmaniasis (Leishmania major infection) in Dutch troops deployed in Northern Afghanistan: Epidemiology, clinical aspects, and treatment. Am J Trop Med Hyg. 2010;83(6):1295-300.

135. Jaffary F, Nilforoushzadeh MA, Siadat A, Haftbaradaran E, Ansari N, Ahmadi E. A comparison between the effects of glucantime, topical trichloroacetic acid 50\% plus glucantime, and fractional carbon dioxide laser plus glucantime on cutaneous leishmaniasis lesions. Dermatol Res Pract. 2016;2016:6462804.

136. García-Hernández R, Manzano JI, Castanys S, Gamarro F. Leishmania donovani develops resistance to drug combinations. PLoS Negl Trop Dis. 2012;6(12):1974.

\section{Publisher's Note}

Springer Nature remains neutral with regard to jurisdictional claims in published maps and institutional affiliations. 